\title{
Timbres amphoriques de Mirmeki
}

\author{
Anna Sadurska
}

Il y a maintenant deux grands centres des recherches scientifiques en épigraphie ceramique. L'un c'est American School of the Classical Studies at Athens avec Virginia Grace, eminente épigraphiste, l'autre à Moscou où travaillent les savants russes groupés autour du Prof. Grakov. Nous essayons maintenant de former aussi notre centre (comme l'ont fait déjà les collègues roumains) à Varsovie puisque nous avons des matériaux archéologiques provenants de nos fouilles en Crimée et en Egypte. Le grand papyrologue polonais, fondateur de l'Institut de Papyrologie à Varsovie, prof. Taubenschlag, disparu hélas cette année répétait souvent qu'il faut trois choses pour former un centre de nouvelles études: les contacts personnels, la bibliothèque et les hommes. La base des toutes les recherches scientifiques en archéologie réside cependant dans les matériaux originaux. Ces matériaux - une collection d'anses amphoriques et de tuiles timbrées - existent déjà au Musée National de Varsovie grâce aux efforts constants de prof. Michałowski, l'initiateur de tous les travaux archéologiques menés par la Pologne depuis une vingtaine d'années. Cette collection s'enrichit chaque année d'une quantité considérable des specimens trouvés dans les fouilles de prof. Michałowski. A présent elle n'est pas nombreuse, mais assez interessante. Elle m'a servie de base à ce communiqué et à deux publications parues en 1956.

Je ne parlerai ici que de timbres sur les anses amphoriques provenants de Rhode et de Sinope. Pour justifier ce choix il faut citer quelques chiffres.

Les fouilles polonaises à Mirmeki en 1956 ont fourni 30 anses timbrées, les fouilles des 1957 ont fourni 200 anses. Nous avons donc ensemble 230 anses timbrées. 172 anses proviennent de Rhode et de Sinope. Tous les autres centres de la production d'amphores ont fourni seulement 58 anses. Parmi ces 58 anses 11 sont d'une provenance incertaine. Il nous reste donc 47 anses pour Thase, Cnide, Pare, Cos, Chersonèse, Heraclée. C'est trop peu pour commencer les études speciales.

Les amphores timbrées servaient pour le transport du vin. Nous avons donc une preuve que Mirmeki était en relations commerciales avec Rhode et Sinope. Ces relations étaient très suivies au II-e siècle avant n. e. Parmi les 18 anses rhodiennes datables (portant les noms d'archontes et des fabricants connus) il y a 16 datant du Пe siècle. Parmi les 54 anses datées 
de Sinope il y en a 47 du II-e siècle. Le deuxième siècle est.l'époque de próspérité de Mirmeki. L'importation des produits alimentaires par les habitants d'une ville qui prospère est tout à fait comprehensible, mais l'importation d'une grande quantité du vin par cette petite ville dans laquelle travaillaient quatre fabriques locales du vin ne l'est pas du tout.

Pourquoi trouvons nous à Mirmeki dans la couche du II-e siècle cette masse d'amphores provenants de Sinope et de Rhode? C'est la même question qui tourmentait J. H. Kent à propos d'anses rhodiennes trouvées dans les domaines des prêtres d'Apollon à Delos. Dans ces domaines-écrit M. Kenton cultivait les vignes et on avait des difficultés sérieuses avec la vente du vin. L'importation de ce produit dans ces circonstances n'est pas vraisemblable. En conclusion J. H. Kent suppose l'importation d'amphores vides. Cette hypothèse est appugée d'ailleur par des inscriptions de Delos concernarit les prix des amphores vides ${ }^{1}$ ). On pourrait supposer que ce fut également le cas pour Mirmeki. On y faisait du vin mais probablement on ne fabriquait pas d'amphores car-l'argile locale était de mauvaise qualité. Les fabricants du vin de Mirmeki étaient done obligés d'acheter les amphores vides pour les remplir du vin. Ils pouvaient les acheter à bon marché à Rhode malgré la necessité de transport par mer, car les marchands rhodiens achetaient le blé dans le Royaume du Bosphore ${ }^{2}$ ). Les navires rhodiens en allant à la Mer Noire pour acheter du blé pouvaient prendre comme fret des amphores vides timbrées et non timbrées qu'ils revendaient en Mirmeki en grande quantité. N'oublions pas que les anses timbrées de Rhode ne constituent qu'un modeste pourcentage dans une masse d'anses rhodiennes sans timbres, mais faciles à reconnaitre grâce à leur qualité d'argile.

Quant aux amphores timbrées Sinope je serais enclin à leur prêter un usage différent. Mirmeki comme toute Bosphore était dépourvue d'oliviers. La ville la plus proche qui pouvait fournir à Mirmeki l'huile d'olive était Sinope $\left.{ }^{3}\right)$. Il me semble donc logique d'admettre que les amphores timbrées de Sinope étaient remplies d'huile. Le texte d'un timbre amphorique contient toujours un élément de datation. A Sinope c'est le nom d'astynome qui la désignait de l'année. C'était donc la date assez précise qui pouvait assurer la frâicheur de l'huile sinopéenne aux clients de Mirmeki. Les amphores non timbrées de Sinope trouvées également en grande quantité à Mirmeki pouvaient être achetées vides pour conserver le vin de la fabrication locale. En parlant de timbres de Sinope il ne faut pas ommettre l'histoire des emblèmes. Parmi les 20 emblèmes différents ornant les tim-

1) J. H. Kent, Stamped amphora handles from the Delian temple estates, Studies presented to D. M. Robinson II, Washington/St. Louis 1953, 128/129.

$\left.{ }^{2}\right)$ В. Ф. Гайдукевич, Боспорское царство, Москва/Ленинград 1949, 88.

3) Гайдукевич 1. с.. 20. 
bres trouvés à Mirmeki il y en a sept qui avaient sûrement des monuments d'art comme prototype. Ce sont: la tête d'Athena Parthenos, l'Athena Lemnia, le Zeus Olympien, la Niké de Samothrace, l'Heracles avec une corne d'abondance, l'éphèbe sur un cheval et un lion. Parmi ces sept emblèmes il $\mathrm{y}$ en a cinq qui correspondent aux monuments d'art grec classique et deux qui viennent de l'époque hellenistique (Niké et Heracles). C'est une preuve de contacts culturels importants entre Sinope et Athènes ainsi qu'avec les autres grands centres de la sculpture grecque.

Pour finir je voudrais tirer une conclusion par rapport à la quantité de timbres que nous avons trouvés à Mirmeki en 1956 et à celle de timbres trouvés l'année suivante. Pendant la première saison de fouilles on a trouvé seulement 29 anses timbrées, pendant la seconde saison qui a également duré quatre semaines nous avons trouvé 200 anses. Cela s'explique parfaitement par la difference qui existe entre deux quartiers de Mirmeki fouillés par l'expédition polonaise. En 1956 nous avons deblayé une fabrique du vin et un quartier d'habitation tandis qu'en 1957 le prof. Michałowski a degagé un quartier commercial avec des boutiques qui donnaient sur une petite place près d'une terrasse fréquentée sans doute par des commerçants. 